\title{
Cultural Passive Defense from the Perspective of Islamic Values with the Entrepreneurial Approach
}

\author{
Mohammad Bagher Babaee Talatappeh ${ }^{1} \&$ Arash Radmehr $^{2}$ \\ ${ }^{1}$ University of Imam Hossein, Tehran, Iran \\ ${ }^{2}$ PhD Student, Department of Management, Qazvin Branch. Islamic Azad University. Qazvin, Iran \\ Correspondence: Mohammad Bagher Babaee Talatappeh, University of Imam Hossein, Tehran, Iran. \\ E-mail: mbbabaee@ihu.ac.ir
}

Received: February 10, 2015

Accepted: March 22, 2015

Online Published: March 27, 2015

doi:10.5539/mas.v10n6p29

URL: http://dx.doi.org/10.5539/mas.v10n6p29

\begin{abstract}
Today, Passive Defense as a necessity and broad area in all aspects of economic, cultural, political, technological and social approach of prevention and deterrence, plays a vital role in preserving Islamic values, preserve the honor of Iran, to reduce vulnerability in key parts of the country as well as promoting resource efficiency and power management in different areas.

In addition to defending the land, passive defense is to defend beliefs and values against the dangers that threaten the country, with increased resistance, maintaining morale and cohesion of the people against the threats, through attention to cultural and religious infrastructure. This research utilizes library studies, content analysis and interviews with experts in the field of Islamic culture, passive defense and entrepreneurship to study and analyze the promotion of passive defense culture from the perspective of Islamic values and the role of the custodian organizations of the cultural and educational sphere in the country in the context of entrepreneurial and innovative actions.
\end{abstract}

Keywords: passive defense, Islamic values, entrepreneurship, culture, cultural entrepreneurship

\section{Introduction}

The Supreme Leader of Iran: "Today the importance of passive defense rule should be better known to the authorities, and the only way to deal with the threats that the domestic situation to be arranged in such a way that the enemy would not be sure of his victory". Man long has been invaded by natural elements like predatory animals and other people. Generally, the influx of people in most countries is in order to use human potential and productivity of the country that has been invaded. Following the human move to the evolution of human knowledge and technology, the technology used in wars has also improved and its concrete example is the invention of the atomic bomb and its use in World War II. Against today's war in the form of software, cultural and biological threats; this is something that even more highlights the necessity of paying attention to the sphere of passive defense, and doing preventive measures and enhance the level of preparedness and awareness across the country and society against these threats and the types of crises including natural disasters and mitigate their probable damage war against modern threats in the form of software, cultural, biological.

One of the most important ways to deal with social and cultural damage caused by cross-border media and foreign media products is providing the social and cultural background for domestic media consumption. In other words, soft equipment and facilities should be used in this field to prevent the creation of undesirable identity for the community. Because people in our society, like many developing or underdeveloped countries, use cross-border and foreign media products through media such as satellite television and the Internet; it is necessary that officials and practitioners of formal and informal institutions provide social and cultural background necessary to deal with the crisis of identity and cultural damage caused by cultural product conflict with Islamic identity and culture of our society; such an action is called cultural passive defense in the current literature of social and human sciences (Babaie Fard, Atash Afrooz, 2014).

In this regard, custodian organizations and institutions for cultural affairs, including the Ministry of Education, IRIB, the Ministry of Culture, the Basij of Islamic Republic of Iran, mosques and universities, etc. have a very important role in intellectual and entrepreneurial promoting of the principles and attitudes of passive defense in 
society and in the context of Islamic values and vision of superior goals. And ditto from another perspective, these organizations are also vulnerable to the threats that the engagement and role as a central issue of this research is discussed.

Course with reviews of past experience from a variety of research in the areas of passive defense, cultural pathology as well as in the form of internal and upstream documents will observe the major duties and strategies of passive defense in cultural organizations. But what is considered as today's generation technologies, the needs of society and wars, and also distinguishes this study is paying attention to entrepreneurs, personal and organizational entrepreneurs which is known as the driving force of the country, the next generation of revolutionary organizations in the management and economic fields in order to achieve value-creating measures, innovative and technological implementation of passive defense in cultural organizations, as well as culturally appropriate products, and considered by the managers and experts in these fields.

\section{Entrepreneurship}

Different definitions offered by experts about the entrepreneurship and the entrepreneur and organizational entrepreneurship, that according to the wide dominance of entrepreneurship in the different fields of science, the diversity of the definitions is something uncontrollable and inevitable, thus providing a complete and comprehensive definition that could receive the consensus views of experts will be difficult and sometimes impossible .

The term entrepreneurship first was coined in French (Karbasi et al., 2002: 27, Erabi, 2003: 17) and is adapted from the French word "Entreprendre" meaning "middlemen" or English phrase "To undertake" meaning of "commitment" (Ahmad Poor Dariani, 2004: 4), which was translated to entrepreneurship in English by Stuart .

Entrepreneurship is considered as the center of gravity of the work and progress in the modern era. We cannot achieve growth and development indices which result from changes in production, productivity, technical and industrial synergies in the field of economy without adequate attention to the issue of entrepreneurial culture development. We should make a special effort for individual capacities of entrepreneurs to take advantage of natural resources and the use of modern technology, in the transition from the traditional to industrial stage. Because on the one hand, they are using new methods on the market to take advantage of tools to achieve high quality goods and services, and on the other hand, entrepreneurship has economic and social impacts such as job creation, improved quality of life, proportional distribution of income, resource utilization and enable them to productivity .

Organizations stakeholders by using case studies and referring to past events try to put organizations in the way to exploit many available opportunities. This approach can be used in many parts of an organization and is applicable in any organization anywhere in the world. Entrepreneurial organizations are focused on the development and implementation of their offensive strategy rather than spend their power to own survival and stabilize the market .

It is obvious that in today's turbulent world, people who benefit high IQ are successful and efficient. Such people can overcome to the problems of life by enjoying their God-given intelligence. The corporate world has also the same situation. Especially in the present era as the time goes ahead, organizations get more complex and managing them becomes more difficult, according to the development of science and technology and the emergence of new needs and challenges. When we accept that in addition to the huge source of human creative smart, intelligent mechanical tool is also involved in the process of organizational performance, the concept becomes more important. So in today's complex organizations, organizational intelligence is the resultant of human active intelligence and artificial intelligence. Certainly managers have no choice but to take advantage of these two intelligent flows for mobility and increase the efficiency of their organization .

Entrepreneur person is someone who can identify and evaluate business opportunities and can gather the necessary resources, exploit them and underpin convenient operation to achieve success .

Entrepreneurship phenomenon has broad dimensions and includes bringing together the technology, training, technical and financial resources. Universities can allocate part of their activities to nurture entrepreneurs. Although universities can only rely on the production and supply of technology and knowledge and put it at the disposal of students and society, but this does not mean success. In other words if universities use the technology in the community and make it available to entrepreneurs and be partly responsible for the practical side of technology, scientific and practical success will be achieved simultaneously. What is now seen as a definition of entrepreneurship is a process beyond the profession and job but a lifestyle.( Mozaffari,2005)

\section{Types of Entrepreneurs}


Entrepreneurship is a process in which a new idea leads to offering a new product to the market by mobilizing resources through the process of creating business that is associated with economic, social and reputation risks. Yet, different categories of entrepreneurship have been conducted by different researchers that some of them are mentioned below:

- The importance based on the personality, social and behavioral contexts has identified two types of entrepreneurs:

\section{Artisan Entrepreneurs}

2. Opportunist Entrepreneurs .

- Ganja with respect to the different types of entrepreneurship presents 5 categories for entrepreneurial activities:

1. Executive Entrepreneurship

2. Opportunistic Entrepreneurship

3. Adventitious Entrepreneurship

4. Formative Entrepreneurship

5. Initiative Entrepreneurship .

In general, entrepreneurship can be divided into 2 main categories:

A) Individual or independent entrepreneurship: Independent entrepreneur starts his/her activity under very limited circumstances independent and with a few part-time or full-time employees and in the early stages may not have even one employee.

B) Organizational or inter organization entrepreneur: Organizational entrepreneurship means developing competencies and opportunities within the organization through various combinations of new resources .

\section{Business and Entrepreneurship Goals in the Islamic Values System}

Entrepreneurship is a concept that has existed since the human creation (Babaei Tala Tape, 2015). The truth is that in the Islamic Republic of Iran, the Islamic vision and revelations resources to businesses are tested factors for a man's religion, and Islamic viewpoint is far from the West materialistic goals. The distance from the individual dimension and entrepreneur's intentions is a virtual and pious instruments that entrepreneur can use as well as a goal and extremity of an entrepreneurial act, which is to satisfy God and people. From the perspective of Islamic values, business and entrepreneurial goals can be expressed in these following cases:

1. Business and Entrepreneurship to meet the family livelihood.

2. Business and entrepreneurship to develop and upgrade own and family life.

3. Business and Entrepreneurship to promote the community.

4. Business and Entrepreneurship to charity and helping the needy.

5. Business and Entrepreneurship to increase wealth for the legitimate use of it.

6. Business and Entrepreneurship to provide unimaginable opportunities for others.

Innovation from the perspective of the Holy Prophet (PBUH):

"God loves the faithful servant who has a new career".

Risk from the perspective of Imam Ali (as):

"If you're afraid of something, do not stop and do it" .

"If you're afraid of something, put yourself in it; because the fear of anything is biger than its own" .

Understanding changes from the perspective of God: The initiator of change is human himself.

"God does not change the status of no one or no nation, unless those people change their status" (Sura Raad, verse 11).

Uncertainty from the perspective of Imam Sadegh (AS):

"We are living in varying circumstances, so work out to the world as if you are eternal, and behave against changing terms and sweep as if you are volant" .

\section{Passive Defense}

Passive defense is the main element of defense and human deterrence against the foreign enemies and disasters. 
So non-armed measures that enhance deterrence, reduce vulnerability, sustaining essential activities, promote national stability and facilitate crisis management against enemy's threats and military actions is called passive defense (Barzegar, Lal Alizadeh, 2011). This type of defense has three main parameters: 1. it is the best way to increase the resistance threshold, 2. it is the most stable, peaceful and cheapest way for defense, 3. it is a solid backing for national sovereignty and prevent vulnerabilities.

For us Muslims, paying particular attention to passive defense is vital because also Quran has ordered us to be prepared for war and save our lives.

Verse 80 of Sura Al-Anbiya says: "and we thought Prophet David (PBUH) to build armor so that you will be protected from harm war". Verse 32 Sura Maida says: Whoever kills someone in the land except for manslaughter or for mischief, it is as if he killed all the mankind; and whoever saves someone's life, it is as if he saved all the mankind.

Passive defense is also considered as a set of unarmed measures that reduces the vulnerability of human resources, buildings, facilities, equipment, and the urban arteries against the enemy's destructive hostilities. On the other hand, by the definition, any unarmed action that reduces the vulnerability of human resources, buildings, facilities, equipment and vital arteries against enemy's destructive hostilities is called passive defense which is definable meaningfully in the face of disasters.

The major functions of passive defense:

Based on the completeness of passive defense in compare with operative defense, different functions can be considered for passive defense.

In terms of the functions of passive defense and their role at all levels and operating areas in the country, passive defense would be proposed in 4 levels of strategic (brain implement), operational (infrastructure), executive (public and municipal) and special level and urgent measures.

Therefore, the emergence of the field of passive defense can happen in all industries, organizations, activities and the country's strategic science and culture at the same time as the focus of analysis in this study has an important role in promoting and institutionalization of passive defense in public and key organizations and as such, organizations in charge of cultural affairs in the country as well as their terms to increase deterrence and prevent enemies need to use the approach and measures of passive defense in their organizations.

Passive purposes:

1. Reduce the ability of the identify systems, targeting and target enemy's offensive weapons.

2. Undertake the vulnerability and Damage reduction and service facilities, equipment and manpower.

3. Maintain the macro-financial assets.

4. Conserve internal power.

5. Foreclose the freedom and initiative from the enemy and create difficult conditions for him at the scene of operations.

6. Save on military spending.

7. Increase resistance threshold of own people and forces against enemy invasion.

8. Impose more costs to the enemy.

9. Make necessary preparations.

10. Preservation of territorial integrity, financial security and country's independence.

6. The importance of Culture

Without a doubt, the highest and greatest element that has a fundamental involvement in existence of any society is its culture. The culture of a community forms the identity and existence of that society. Although the society has strong economic, political, industrial and military dimensions, if there is culture deviation, it will be absurd. Once society culture is dependent on hostile culture, the other aspects of the community will also move to the opposite side inevitably, and eventually will be depreciated in it and will lose its existence in all dimensions, because the independence and existence of the society stems from the independence of its culture and it is simple-mindedness to suppose that despite cultural dependence, independence in other dimensions or one of them would be possible.

The emphasis on efforts to promote society's culture and have cultural concerns about the country's situation are 
resulted from the Islamic perspective on the issues of culture and determining impact of cultural issues on the present and future conditions of the society.

The extent of cultural territory is as much as human social life and includes all reserves and heritage of thought (theoretical reason) and intellectual and manual products (practical reason) of man from the beginning to today. Culture rules and governs in all aspects of life and in the light of it; human life is distinguished from animal life. Culture is a certain environment which human moves in it, foster its inspirations and adapt its authority to influence by communications. Culture is a water flow, including colors, melodies, habits, shapes, songs and motions that form specific orientation of man's life, powers his thought and imagination, inspires his genius and develops his creative abilities. Culture is the organic connection between human and the framework that surrounds him. Culture is theme of any group, organization, and community gatherings. In today's common terms, culture is known as hardware and software of various human gatherings.

Newer experts including experts in cultural studies and sociology new thinkers have new approaches to the identity and culture and definition of culture. They also criticize the former approaches on the identity and culture, the independence, the relativity and changeability of culture, and do not consider it as a dependent variable in social changes (Negus, 2007).

By reviewing the variety classifications of cultures and other things can explain that they all refer to the appearance of life or to a certain way of life. Therefore, comprehensive classifications and Benefits of culture must be stated based on the types of Dos and don'ts ruling on people's lives. And since people's Dos and don'ts are based on their value system and worldviews, culture can be divided into two main parts:

1. Divine culture: a culture based on the values of the paranormal and stems from revelation spring.

2. Non-divine culture: a culture that arose from the leakage of the human mind and all the documentation are resulted from the scientific (empirical) human achievements do not believe in the paranormal.

\section{Elements of Culture}

Culture has a systematic organization. The concept of system would envisage the existence of components and interactions between them or to the structure and process. Cultural construction usually includes cultural element, cultural combination and cultural fields. The most small subject and units to define and recognize is called "cultural element", proportionality and accompany of them is called "cultural mix" and collection of cultural mix in an area that has a distinct form and range is called "cultural area".

The cultural element is the smallest unit of a culture. A cultural element is formed of a component or part that is not dividable to other elements and parts. Some cultural elements are a material simple object, such as: Ring, canes, etc. But others are not material, but a pattern of behavior such as: shacking hand, greeting, prayer, etc. Cultural elements are not defined same by different people.

"Leslie a. White" believes that any cultural structure consists of four elements: industrial (technology), social (customs, institutions, rules and behavior patterns of people with each other), faith (belief) and attitude (the feelings or ideas to expression) and explains that the technology is the basic foundation of the cultural system and its changes leads to change in the other sectors. The driving force of culture lies in its technology and if technology is so much powerful that it can make its way through his dam society, if so it will create a new system and if not, then it have to be constrained in the bottlenecks.

Allama Muhammad Taqi Jafari's believes culture has two fixed and variable elements. Changing principles are based on variable human needs over time which changes according to different conditions. Fixed cultural elements are based on human natural and inherent needs and the passage of time will not impact on their nature. These elements and principles are:

1. Element and principle of perfection-seeking and passion to it;

2. Element and principle of respect, which in human common culture is mentioned by titles such as altruism, love of people and kindness;

3. Element and principle of human intense longing to have a decent and worthy life;

\section{Cultural Invasion}

Cultural Invasion is any movement of the enemy in order to alter or distort the values, attitudes and human actions of a society. In other words, cultural invasion is that a nation takes the dominant culture of a nation and imposes them another culture, so that the invaded nation will culturally be dominated by the culture of invasive nation. Cultural threats are as follows: 
- Cultural threats and internal hypocrites

- Cultural threats and administration

- Cultural threats and the performance of authorities

- Cultural threats and universities

- Cultural threats and youth

- Cultural threats and people

- Cultural threats and global arrogance

\section{Cultural Passive Defense}

Culture passive defense is a set of non-armed measures that lead to increase in enemy deterrence, reducing the vulnerability of critical infrastructure of the country's cultural sector, continuity of essential cultural activities, promoting national stability, facilitate the management of crisis caused by enemy threats, cultural and psychological operations against enemy invasion. (Tamanaie Far, Cheshm Berahi, 2014)

Research shows that after the World War II threats are divided to both hardware and software divisions. The hardware dimension is the military issues that are expensive. On the other hand, there is software dimension; this dimension is the cultural and social system of a country. Movement of a community or human depends on its dominant culture. Growth or decline of the individual or community is a direct consequence of its individual or collective culture. (Bidgoli, 2014)

\section{Cultural passive defense purposes are as follows:}

- Reduce the vulnerability of critical infrastructure in culture and advertisement fields of the Country

- Sustainability of cultural and national identity

- Retrofit systems and cultural structures against enemy's threats

- Managing the crisis which are caused by enemy's threats and cultural and psychological operation

- Community awareness about the importance of passive defense

- Organizing the cultural-promotional capabilities according to national defense purposes across the country (Hashemi fesharaki, 2010)

- Deal with the crisis and the cultural invasions

- $\quad$ Promote the tolerance threshold of people (reinforcing the beliefs and desired values)

\section{The Coping Strategies with the Points of Cultural Damage in the Form of Passive Defense}

\section{- Cultural and spiritual services:}

The first and most important way to deal with the pathology of cultural is offering the spiritual services to the community, because if religious and spiritual culture would be dominated in society and aspects of people's life, many problems and the mess will be solved in different ways. According to Imam Khamenei "If we can strengthen it in ourselves, all the power equations power in the world would benefit us".

The most important service to young people about the cultural and spiritual dimension is that their thoughts grow up in order to advance the goals of Islam and the political and economic independence of the country, so that efflorescence of their talent will result in the best future for the Islamic nation and the country.

The cultural and spiritual authorities are responsible that through careful planning and quick action, foster young generation, save them from moral corruption and cultural invasion and guarantee the Islamic Revolution.

- Preparing the background for employment: The main causes of corruption are unemployment and the self-indulgence. Marriage backgrounds should be prepared so that youth instinct of lust will be controlled and half of their religion will be saved.

- Strengthening the religious dimension in youth culture, especially paying attention to prayer.

- Guide the misguided and steer the offenders which are important tasks of the country's cultural authorities. 
- Raise the scientific and cultural level of students.

- Islamization the universities in its real sense.

- The inclusion of necessary materials in leisure time of students.

- $\quad$ Acquaint the public with the political issues of the country and the world.

(Educational, cultural deputy of Basij Resistance Force, 2003)

\section{Results and Discussion}

Without a doubt, the highest and greatest element which has a fundamental involvement in any society existence is the culture of the community. And thus, culture, building culture and hedging of culture custodian organizations as a basic action arises in in the area of passive defense.

According to clause 7 of General Policies of the passive defense, culture and education in the field of using the principles of passive defense are emphasized. Also based on clause 11, the principles of dealing with enemy software threats and other new ones are considered in order to maintain the protection of information networks. As mentioned in clause 2, the two principles of passive defense which are mandatory include desensitization and deceive the enemy in order to achieve deterrence as well as the National promotion and sustainability. A significant part of these items is assigned to culture Custodians of the country.

In general it can be concluded that strengthen the culture is itself a very important factor in strengthening the passive defense. Culture has different meanings, but today can be defined as software rather than hardware. According to Hall, culture implies on the production and exchange of ideas and concepts between members of the community or groups. John Hartley also defined culture as a production and reproduction of social feelings, meanings and self-conscious. Hence, culture refers to the process of creation and the symbolization. (Dehghani Firozabadi, 2011)

Several suggestions to enhance passive defense on the basis of cultural development are:

- Making television programs to strengthen the foundations of values and norms of society.

- Use of ethnic and cultural diversity capacity to deal with the cultural invasion and to minimize tensions and possible opportunities for the enemy through holding conferences for cultural integration and cultural communications.

- Drawing up of the movies to explain the components of cultural development, and in other words promotion of cultural factors in the society, such as book and newspaper reading.

- Increase the general study and related issues through offering cultural products with reasonable prices.

- Publishing books about the necessity of understanding the passive defense and familiarity with the risks.

- Explaining the components of the soft and silent war.

- Promoting cultural elements such as the socially desirable behaviors including cooperation, sacrifice and forgiveness (Niazi, Bidgoli, Arani, 2014).

Therefore, culture as a shield in the society and foundation of all the subjects and development of countries, has a creative and entrepreneurial nature in its heart. On the other hand, the Islam-based approach is to reducing costs and losses and staves off the threat and its corresponding concepts in a more modern view means the passive defense. Also the variety and complexity of cultural threats and adopting innovative and entrepreneurial approaches to deal with different situations are proposed.

The conceptual model to describe the position and the relationship between these three concepts is presented with regard to the analysis of content and research history in the field of passive defense, culture and entrepreneurship.

In this context, entrepreneurship with an innovative approach and value creation can play a crucial role in achieving the goals and values of Islam in the field of passive defense. Thus, as a result of cultural resources which are studied in this research, the concept of passive defense is explained with an entrepreneurial approach to the following definitions and guidelines:

- Cultural entrepreneurship in the field of passive defense.

- Discover, absorption and utilization of money making cultural opportunities.

- Launch new businesses in the field of culture.

- Produce new cultural products. 
- Creative destruction in the society to create something worthwhile

- $\quad$ Produce and supply cultural and artistic products in an innovative way in order to revive cultural values.

- Adopt value-added, creative and God-centered approach in all aspects and stages of cultural defense.

- Resources management and maximize the efficiency in custodian organizations of culture.

- Design and implementation of innovative cultural programs to immunize and response to cultural threats.

\section{Reference}

Babaei, T. T., MB, (2015). Management and entrepreneurship in Islamic values, Pooia Anish publication.

Barzegar, A. A., \& Lal, A. (2010), Soft war, Islamophobe computer games and passive defense, studies on soft power.

Bidgoli, E. A. (2014). Explanation of passive defense based on culture. National Conference of Passive Defense and Humanities.

Dehghani, F. (2010). Power technologies in the soft war, Strategic Studies Quarterly, No.1.

Department of cultural, educational of Basij. The movement of public service (2003) Publications: Peik Sobhan.

Fard, A. B., \& Samira, A. A. (2014). Identity, identity crisis and cultural passive defense.

Fesharaki, H., \& Seyed, J. (2010). The position of culture in passive defense, Social Science Book of the Month.

Mozaffari, F., (2005). New components of strategic culture, Journal of defense strategy.

Negus, K. (2007). Rethinking Creative Production away from the Cultural Industries, in:Media and Cultural Theory, Edited by; James Curran and David Morley, London and New York, Routledge.

Niazi, M., Almasi, B. E., \& Hosseini, Z. A. S. (2014), The role of cultural development in passive defense.

Tamanaie, F., Mohammad, R., Cheshm, B. S., (2014). The culture from the perspective of passive defense.

\section{Copyrights}

Copyright for this article is retained by the author(s), with first publication rights granted to the journal.

This is an open-access article distributed under the terms and conditions of the Creative Commons Attribution license (http://creativecommons.org/licenses/by/3.0/). 